Cahiers $d u$ MONDE RUSSE

\section{Cahiers du monde russe}

Russie - Empire russe - Union soviétique et États indépendants

$43 / 4 \mid 2002$

Intellectuels et intelligentsia

\title{
Général Petrenko, Avant et après Auschwitz
}

\section{Alain Blum}

\section{OpenEdition \\ Journals}

Édition électronique

URL : https://journals.openedition.org/monderusse/4060

DOI : 10.4000/monderusse.4060

ISSN : $1777-5388$

Éditeur

Éditions de l'EHESS

Édition imprimée

Date de publication : 30 décembre 2002

Pagination : 808-810

ISBN : 2-7132-1796-2

ISSN : $1252-6576$

\section{Référence électronique}

Alain Blum, "Général Petrenko, Avant et après Auschwitz », Cahiers du monde russe [En ligne], 43/4 I 2002, mis en ligne le 18 juin 2009, consulté le 04 septembre 2022. URL : http://

journals.openedition.org/monderusse/4060; DOI : https://doi.org/10.4000/monderusse.4060

Ce document a été généré automatiquement le 4 septembre 2022

Tous droits réservés 


\title{
Général Petrenko, Avant et après Auschwitz
}

\author{
Alain Blum
}

\section{RÉFÉRENCE}

Général PETRENKO, Avant et après Auschwitz. Suivi de Ilya ALTMAN et Claudio

INGERFLOM, Le Kremlin et l'holocauste, 1933-2001. Paris, Flammarion, 2002, 285 p.

(trad. de : Do i posle Osvencima, Moscou, Bibliothèque russe de l'Holocauste, 2000)

1 Vasilij Petrenko fut l'un des quatre généraux qui libérèrent Auschwitz. Le seul survivant aujourd'hui. Ne cherchons pas, dans ce livre, une étude des ressorts profonds de l'attitude du pouvoir soviétique vis-à-vis des camps d'extermination, même si la postface d'Ilya Altman et Claudio Ingerflom constitue une belle synthèse de cette question. Il s'agit plus d'une autobiographie, née du souci de comprendre l'ignorance dans laquelle lui-même, Petrenko, resta quant à cette question. Il s'agit aussi, à l'origine, d'un ouvrage écrit par un Ukrainien, Petrenko, destiné à présenter au public russe ce qui fut fait, durant toute cette période, par le pouvoir soviétique. Cela n'est pas neutre, car Petrenko n'est pas juif (au sens « soviétique » du terme), et cette distinction est d'importance en Russie pour traiter de ces questions.

2 Comme le soulignent Ilya Altman et Claudio Ingerflom, une première lecture de cet ouvrage « concerne la sociologie et l'anthropologie de l'Armée rouge: qui étaient ces officiers ? comment pensaient-ils? quelles étaient leurs valeurs?». Plus encore, nous dirions qu'une telle lecture offre une belle représentation de la manière dont ceux qui participèrent à l'histoire soviétique - jusqu'à être les premiers à entrer dans les camps, ou jusqu'à accompagner des détenus du NKVD, ou à être des témoins privilégiés de la collectivisation, de la famine de 1933, de toutes les répressions, etc. - la parcoururent au long d'une carrière presque ininterrompue, sans faire de ces violences des questions, sans que tout cela suscite le moindre doute. Petrenko accomplit sa carrière en militaire qui ne réagit que lorsque des ordres lui paraissent aberrants. Il témoigne de la délation la plus 
simple (un élève officier retirant du feu un dessin humoristique qu'il avait commenté par exemple, et le donnant à ses supérieurs) comme d'un incident parmi d'autres. Il fait état des arrestations massives durant l'année 1937, parmi les gradés du régiment où luimême, seulement lieutenant-chef, n'avait jamais imaginé pouvoir être inquiété. Il rapporte ces circonstances comme une simple étape de sa carrière dont l'effet fut l'accélération de sa promotion sans qu'il la provoque ou l'attende. Cette inertie manifeste à plusieurs reprises dans la poursuite de sa carrière pose la question du ressort de ces violences, extérieures aux personnes qui en sont les témoins passifs, mais aussi sources de profits secondaires importants.

3 La seconde lecture tient à l'attitude du pouvoir soviétique central, et surtout de Stalin, vis-à-vis des camps d'extermination. Sans doute, ici, le témoignage est-il issu de l'inquiétude de comprendre si les armées soviétiques tardèrent à effectuer cette libération. À une réponse d'évidence, que l'auteur possédait déjà - réponse par la négation -, se substitua peu à peu un doute qui le conduisit à explorer les archives et à devenir l'un des historiens de cette période, autant que son témoin.

4 Il s'agit bien entendu d'une autobiographie tardive, fondée sur un travail d'archives autant que sur la mémoire. Mais une autobiographie intéressante, tant le choix d'une écriture linéaire le conduit à retracer avec conviction ce parallèle entre une « Histoire » soviétique, dont on connaît aujourd'hui le caractère dramatique et violent, et au sein de laquelle la collectivisation, les impérities militaires, conséquences de la répression qui frappa tous les officiers en 1937, conduisirent à des pertes immenses, etc. - phénomènes dont l'ampleur et la violence sont bien connues -, et l'histoire personnelle d'un témoin direct qui passe à côté ou au travers de tous ces événements. Ce contraste est saisissant, même écrit plus d'un demi-siècle plus tard. C'est là, sans aucun doute, l'un des grands apports de cet ouvrage, qui en fait un outil de réflexion important.

5 La postface d'Ilya Altman et de Claudio Ingerflom offre au lecteur une réflexion générale sur la politique de Stalin vis-à-vis de l'extermination des juifs entre 1933 et la fin de la Seconde Guerre mondiale. Elle n'évoque que très rapidement, en revanche, et malgré le titre ( « Le Kremlin et l'holocauste »), l'après-Seconde Guerre mondiale, période, il est vrai, mieux connue. Son grand intérêt est de faire connaître de nombreuses sources et ouvrages russes qui ont renouvelé en profondeur, ces dernières années, la question de l'attitude soviétique face à la politique nazie à l'égard des juifs, tout en engageant un questionnement comparatif et en prenant en compte ce que l'on connait aujourd'hui de la position des Alliés sur cette question. Le texte est construit autour d'une thèse principale: la politique soviétique vis-à-vis de l'extermination des juifs entre 1933 et 1945 ne peut se réduire à une attitude qui serait entièrement fondée sur un antisémitisme profond et réel de Stalin. Altman et Ingerflom montrent à quel point au contraire celle-ci est très politique, opportuniste, mais aussi répondrait, selon eux, dans la seconde moitié de la guerre, à un souci d'utiliser le patriotisme russe ainsi qu'à la prise en compte de l'antisémitisme profond de la population des territoires contrôlés par les nazis puis libérés.

6 Restent enfin plusieurs informations nouvelles, même si certaines d'entre elles ont été publiées auparavant dans des ouvrages russes. Ainsi on apprend qu'avant d'avoir le projet de déporter les juifs vers Madagascar, les Allemands avaient proposé aux Soviétiques de les déporter au Birobidjan, proposition déclinée par ces derniers. On découvre aussi la complexité de cette attitude soviétique, qui parfois laisse passer des juifs sur son sol, voire en reçoit, parfois ferme ses portes ou exclut l'évacuation des zones orientales pour éviter d'avoir à définir une politique officielle vis-à-vis des juifs. On est définitivement 
convaincu par la précision de l'information qui était reçue sur les massacres et les camps d'extermination, mais aussi par la volonté manifeste de ne pas faire mention des juifs tout le long de cette période, et surtout à partir de 1942. On connait beaucoup mieux le niveau d'information des différents responsables militaires et politiques sur les crimes nazis. Enfin, il apparait désormais clairement, tant à la lecture de cette postface que de l'autobiographie de Petrenko, que l'État-Major et Stalin lui-même n'ont rien fait pour accélérer la libération d'Auschwitz ou d'autres camps d'extermination, qui ne furent donc qu'une étape dans la marche vers l'Ouest mais en aucune façon un objectif spécifique.

7 On est en revanche un peu moins convaincu par l'argument selon lequel cette exclusion tiendrait pour partie à l'antisémitisme populaire, pris en compte par les dirigeants, même si, pour Altman et Ingerflom, ce n'est qu'une hypothèse parmi d'autres. Ces auteurs soutiennent d'ailleurs, en s'appuyant sur d'autres sources, que cela tenait aussi à la volonté des dirigeants de se démarquer du discours nazi associant juifs et communistes, ou à leur souhait de retrouver un discours unificateur sur le thème des souffrances et des massacres. De la même manière, on regrettera le traitement vraiment très rapide, et qui n'apporte rien de nouveau, des années postérieures à 1945, ou même de la période qui débute en 1943.

8 Malgré ces réserves, ou plutôt ces regrets, ce livre est un ouvrage important, qui offre une très belle synthèse de la politique soviétique face à l'extermination des juifs, tout en dépassant cette question pour fournir une réflexion sur l'attitude des Soviétiques dont la carrière se situe durant ces périodes tragiques qui s'étendent de 1930 à 1950. 